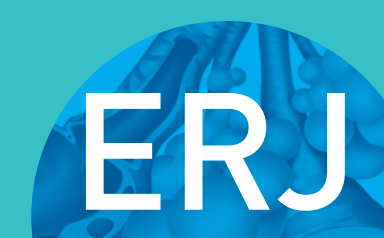

open research
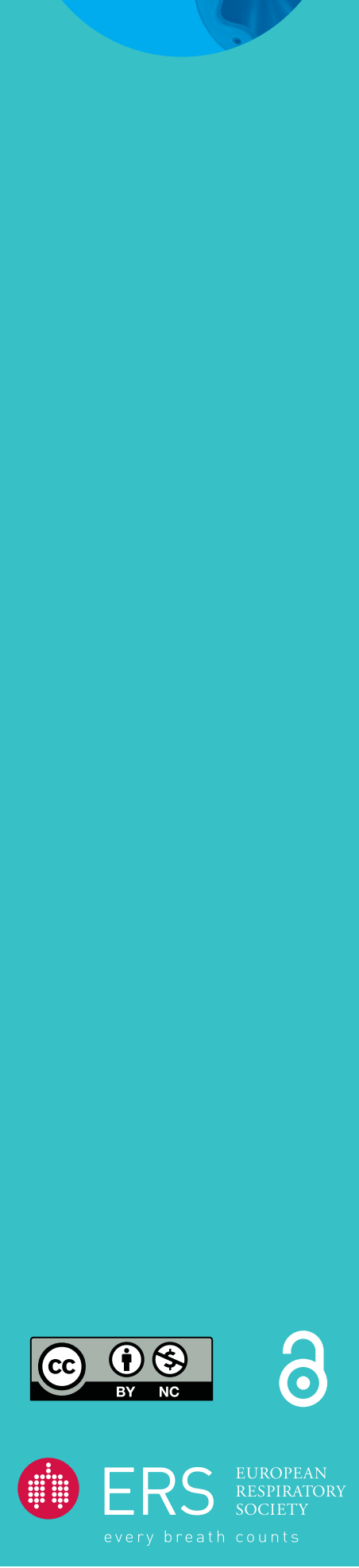

\section{Dysregulated alveolar function and complications in smokers following oesophagectomy}

\author{
Sebastian T. Lugg ${ }^{1,4}$, Kerrie A. Alridge ${ }^{1,4}$, Phillip A. Howells ${ }^{1}$, Dhruv Parekh (1) ${ }^{1}$, \\ Aaron Scott ${ }^{1}$, Rahul Y. Mahida ${ }^{1}$, Daniel Park ${ }^{3}$, Olga Tucker ${ }^{3}$, Fang Gao ${ }^{1}$, \\ Gavin D. Perkins ${ }^{2}$, David R. Thickett ${ }^{1,5}$ and Rachel C.A. Dancer ${ }^{1,3,5}$
}

Affiliations: ${ }^{1}$ Birmingham Acute Care Research Group, Institute of Inflammation and Ageing, University of Birmingham, Birmingham, UK. ${ }^{2}$ Warwick Medical School, University of Warwick, Coventry, UK. ${ }^{3}$ Birmingham Heartlands Hospital, University Hospitals Birmingham NHS Foundation Trust, Birmingham, UK. ${ }^{4}$ These two authors are joint first authors. ${ }^{5}$ These two authors are joint final authors.

Correspondence: Rachel C.A. Dancer, Institute of Inflammation and Ageing, University of Birmingham, Mindelsohn Way, Edgbaston, Birmingham, B15 2TH, UK. E-mail: r.dancerlabham.ac.uk

ABSTRACT Acute respiratory distress syndrome (ARDS) has a significant impact on post-operative morbidity and mortality following oesophagectomy. Smoking is a risk factor for the development of ARDS, although the mechanism is unclear. We examined the effect of smoking on alveolar and systemic inflammation, in addition to alveolar-capillary permeability, leading to ARDS in patients undergoing oesophagectomy.

We compared clinical, biomarker and PiCCO system data between current smokers $(n=14)$ and exsmokers $(\mathrm{n}=36)$ enrolled into a translational substudy of the BALTI-P (Beta Agonist Lung Injury Trial Prevention) trial.

Current smokers compared with ex-smokers had significantly higher numbers of circulating neutrophils, elevated bronchoalveolar lavage (BAL) interleukin (IL)-1 receptor antagonist (IL-1ra), soluble tumour necrosis factor receptor-1 and pre-operative plasma soluble intercellular adhesion molecule-1, and lower BAL vascular endothelial growth factor and post-operative plasma IL-17 $(\mathrm{p}<0.05)$. On post-operative day 1 , current smokers had higher extravascular lung water index (9.80 versus $7.90 ; \mathrm{p}=0.026)$ and pulmonary vascular permeability index (2.09 versus $1.70 ; \mathrm{p}=0.013)$. Current smokers were more likely to develop ARDS (57\% versus 25\%; $\mathrm{p}=0.031$ ) and had a significantly reduced post-operative median survival (421 versus 771 days; $\mathrm{p}=0.023$ ).

Smoking prior to oesophagectomy is associated with dysregulated inflammation, with higher concentrations of inflammatory mediators and lower concentrations of protective mediators. This translates into a higher post-operative inflammatory alveolar oedema, greater risk of ARDS and poorer long-term survival.

@ERSpublications

Patients who smoke at the time of oesophagectomy have dysregulated immune function, greater post-operative alveolar oedema, higher incidence of ARDS and poorer long-term survival http:// ow.ly/EsEh30nbO0R

Cite this article as: Lugg ST, Alridge KA, Howells PA, et al. Dysregulated alveolar function and complications in smokers following oesophagectomy. ERJ Open Res 2019; 5: 00089-2018 [https:// doi.org/10.1183/23120541.00089-2018].

This article has supplementary material available from openres.ersjournals.com

Received: June 132018 | Accepted after revision: Dec 192018

Copyright $\odot E R S$ 2019. This article is open access and distributed under the terms of the Creative Commons Attribution Non-Commercial Licence 4.0. 


\section{Introduction}

Oesophagectomy is associated with a high burden of post-operative morbidity and mortality with attendant long-term health and economic costs [1-4]. Post-operative pulmonary complications including acute respiratory distress syndrome (ARDS) are common, and contribute significantly to the burden of post-operative morbidity and mortality [5, 6]. The reported incidence of ARDS post-oesophagectomy is variable and the reasons behind this heterogeneity are not clear. The reported incidence in the BALTI-P (Beta Agonist Lung Injury Trial Prevention) trial from which the cohort in this current study was drawn was $25.3 \%$ [7].

Smoking has recently been identified as a risk factor for the development of ARDS in nonpulmonary sepsis, following trauma and lung transplant [8-10]. The mechanism underlying this association is unclear, although cigarette smoke exposure is known to adversely alter the permeability of the pulmonary epithelium [11] and endothelium [12], and increase alveolar inflammation [13]. Recent evidence has demonstrated that smokers have an exaggerated disruption of the alveolar-capillary membrane and dysregulated cytokine release in response to nebulised Escherichia coli lipopolysaccharide compared with nonsmokers [14].

No clear association has been demonstrated between smoking and the risk of ARDS following oesophagectomy. This study compared pre- and post-operative plasma biomarkers, post-operative bronchoalveolar lavage (BAL) fluid biomarkers, and PiCCO system measures of alveolar oedema between smokers and nonsmokers undergoing oesophagectomy, aiming to assess the relationship between pre-operative smoking status and post-operative ARDS and mortality. It was hypothesised that current smokers would have higher BAL inflammatory markers, higher measures of alveolar oedema, and higher post-operative ARDS and mortality.

\section{Methods}

Study subjects

Data from ex-smokers and current smokers enrolled into a translational substudy of the BALTI-P trial were included $[7,15]$. Patients with unresectable disease at surgery were excluded from analysis. Patients were asked to self-report their smoking status at the pre-operative assessment clinic 1-2 weeks prior to surgery. Current smokers were defined as patients who were self-reported cigarette smokers at the pre-operative assessment clinic. Ex-smokers were defined as patients who stated they had smoked in the past but no longer did so. The small number of patients who had never smoked were excluded from the analysis $(\mathrm{n}=6)$.

\section{Data collection}

Clinical and demographic data were collected prospectively from the patient's medical records. Full blood counts taken as part of routine clinical care were compared to investigate the level of systemic inflammation in the immediate post-operative period. Not all patients had blood drawn for full blood count on each post-operative day. BAL samples were collected at the end of the operation before extubation using the methods previously described [16]. Supernatant was extracted by centrifugation and analysed. The BAL supernatant was frozen at $-80^{\circ} \mathrm{C}$ and batch analysis of levels of cytokines, including interleukin (IL)-1 receptor antagonist (IL-1ra), IL-1 $\beta$, IL-6, IL-8, surfactant protein D (SPD), soluble receptor for advance glycation end-products (RAGE), tumour necrosis factor (TNF)- $\alpha$, soluble TNF receptor-1 and -2 (TNFR1 and TNFR2), and vascular endothelial growth factor (VEGF), determined using Luminex technology (Millipore, Billerica, MA, USA). PiCCO readings (Pulsion, Feldkirchen, Germany), including cardiac index, extravascular lung water index (EVLWI) and pulmonary vascular permeability index (PVPI), were measured immediately pre-operatively, immediately post-operatively and on the morning after the operation (post-operative day 1). As this cohort of patients was diagnosed prior to the publication of the Berlin criteria, throughout the paper we have used ARDS to indicate patients meeting criteria for acute lung injury or ARDS according to the definition of the American European Consensus Conference [17].

\section{Statistical analysis}

Data were analysed using Prism version 6 (GraphPad, La Jolla, CA, USA). Continuous data were analysed for normality using the D'Agostino-Pearson omnibus normality test, and the appropriate parametric or nonparametric test was performed to detect differences in biochemical and clinical outcomes between current and ex-smokers at the time of the operation. Categorical data were assessed using the Chi-squared test. Survival was analysed using a Kaplan-Meier survival curve, the Gehan-Breslow-Wilcoxon test and log-rank hazard ratio assessment. 


\section{Results}

50 patients (14 current smokers and 36 ex-smokers) were included. Baseline data comparisons between current and ex-smokers are summarised in table 1. Current smokers were statistically more likely to be younger, with a lower body mass index (BMI) than ex-smokers. There was no significant difference in sex, forced expiratory volume in $1 \mathrm{~s}(\mathrm{FEV} 1) \%$ pred or $\mathrm{FEV} 1 /$ forced vital capacity ratio between current and ex-smokers. There was no significant difference in any of three pre-operative risk assessment scores, i.e. modified Glasgow Prognostic Score, pre-operative neutrophil/lymphocyte ratio or pre-operative platelet/ lymphocyte ratio.

\section{Circulating neutrophil count}

Current smokers had significantly higher numbers of circulating neutrophils on post-operative days 1-3 with no significant difference in lymphocyte or platelet count (figure 1).

\section{Biochemical data}

An insufficient BAL sample for analysis was obtained in one patient. Current smokers had higher numbers of alveolar macrophages in BAL fluid than ex-smokers (median (interquartile range (IQR)) 100029 (40178-178043) versus 45000 (24146-73260) cells. $\left.\mathrm{mL}^{-1} ; \mathrm{p}=0.025\right)$. In contrast to the plasma compartment, there was no significant difference in numbers of BAL neutrophils between current smokers and ex-smokers (median (IQR) 18996 (1128-91800) versus 4378 (740-90909) cells $\mathrm{mL}^{-1} ; \mathrm{p}=0.517$ ). Current smokers had significantly higher concentrations of IL-1ra (median (IQR) 51.0 (27.8-123.8) versus 10.1 (0.2-64.6) $\mathrm{pg} \cdot \mathrm{mL}^{-1} ; \mathrm{p}=0.008$ ) and TNFR1 (median (IQR) 270.5 (168.5-367.3) versus 166.8 (112.4-253.1) pg. $\mathrm{mL}^{-1} ; \mathrm{p}=0.030$ ), and significantly lower levels of VEGF (median (IQR) 94.1 (24.0-184.1) versus 151.0 (104.4-280.4) pg. $\mathrm{mL}^{-1} ; \mathrm{p}=0.018$ ) in BAL fluid compared with ex-smokers (figure 2). Current smokers had significantly higher pre-operative plasma concentrations of soluble intercellular adhesion molecule (ICAM)-1 than ex-smokers (median (IQR) 103.5 (63.9-133.0) versus 56.0 (35.1-86.4) pg. $\mathrm{mL}^{-1}$; $\mathrm{p}=0.003$ ), but there was no significant difference post-operatively. Plasma concentrations of IL-17 were generally lower in current smokers than ex-smokers, with a significant difference post-operatively (median (IQR) $2.64(0.52-182.8)$ versus $\left.36.8(6.12-192.6) \mathrm{pg} \cdot \mathrm{mL}^{-1} ; \mathrm{p}=0.043\right)$. There was no significant difference in

\begin{tabular}{|c|c|c|c|}
\hline & Ex-smokers & Current smokers & p-value \\
\hline Subjects & 36 & 14 & \\
\hline Male & $31(86)$ & 13 (93) & 0.663 \\
\hline Age years & $65.5 \pm 9.7$ & $51.9 \pm 8.1$ & $<0.0001$ \\
\hline BMI $\mathrm{kg} \cdot \mathrm{m}^{-2}$ & $26.0(23.8-28.4)$ & $22.0(18.2-24.7)$ & 0.002 \\
\hline FEV $1 \%$ pred & $82.8 \pm 23.3$ & $93.1 \pm 21.2$ & 0.153 \\
\hline FEV $1 / F V C \%$ & $68.5(61.9-75.4)$ & $63.6(52.4-70.3)$ & 0.086 \\
\hline Pack-years & $31.1(17.7)$ & $49.6(30.5)$ & 0.010 \\
\hline \multicolumn{4}{|l|}{ Histological diagnosis } \\
\hline Adenocarcinoma & $28(77.7)$ & 9 (64.3) & 0.473 \\
\hline Squamous & 8 (22.3) & 5 (35.7) & \\
\hline \multicolumn{4}{|l|}{ Tumour location } \\
\hline Lower oesophagus & $27(75)$ & 9 (64.2) & 0.724 \\
\hline Upper or mid oesophagus & $6(16.7)$ & $3(21.4)$ & \\
\hline Unknown & $3(8.3)$ & 2 (14.3) & \\
\hline \multicolumn{4}{|l|}{ Cancer staging } \\
\hline $\mid \mathrm{B}, \| \mathrm{A}$ or $\| \mathrm{B}$ & 15 (41.7) & $6(42.9)$ & 0.939 \\
\hline IIIA & 21 (58.3) & $8(57.1)$ & \\
\hline \multicolumn{4}{|l|}{ ASA grade } \\
\hline 2 & $26(72.2)$ & 13 (92.9) & 0.148 \\
\hline $3-4$ & $10(27.8)$ & $1(7.1)$ & \\
\hline $\mathrm{mGPS}=1$ & $5(14)$ & $3(21)$ & 0.670 \\
\hline Pre-operative NLR & $2.75(2.07-3.15)$ & $2.61(1.68-3.12)$ & 0.479 \\
\hline Pre-operative PLR & 163.3 (130.7-207.3) & $160.3(113.4-252.6)$ & 0.613 \\
\hline
\end{tabular}

Data are presented as $n, n(\%)$, mean $\pm S D$ or median (interquartile range), unless otherwise stated. BMI: body mass index; FEV1: forced expiratory volume in $1 \mathrm{~s}$; FVC: forced vital capacity; ASA: American Society of Anesthesiologists; mGPS: modified Glasgow Prognostic Score; NLR: neutrophil/lymphocyte ratio; PLR: platelet/lymphocyte ratio. 

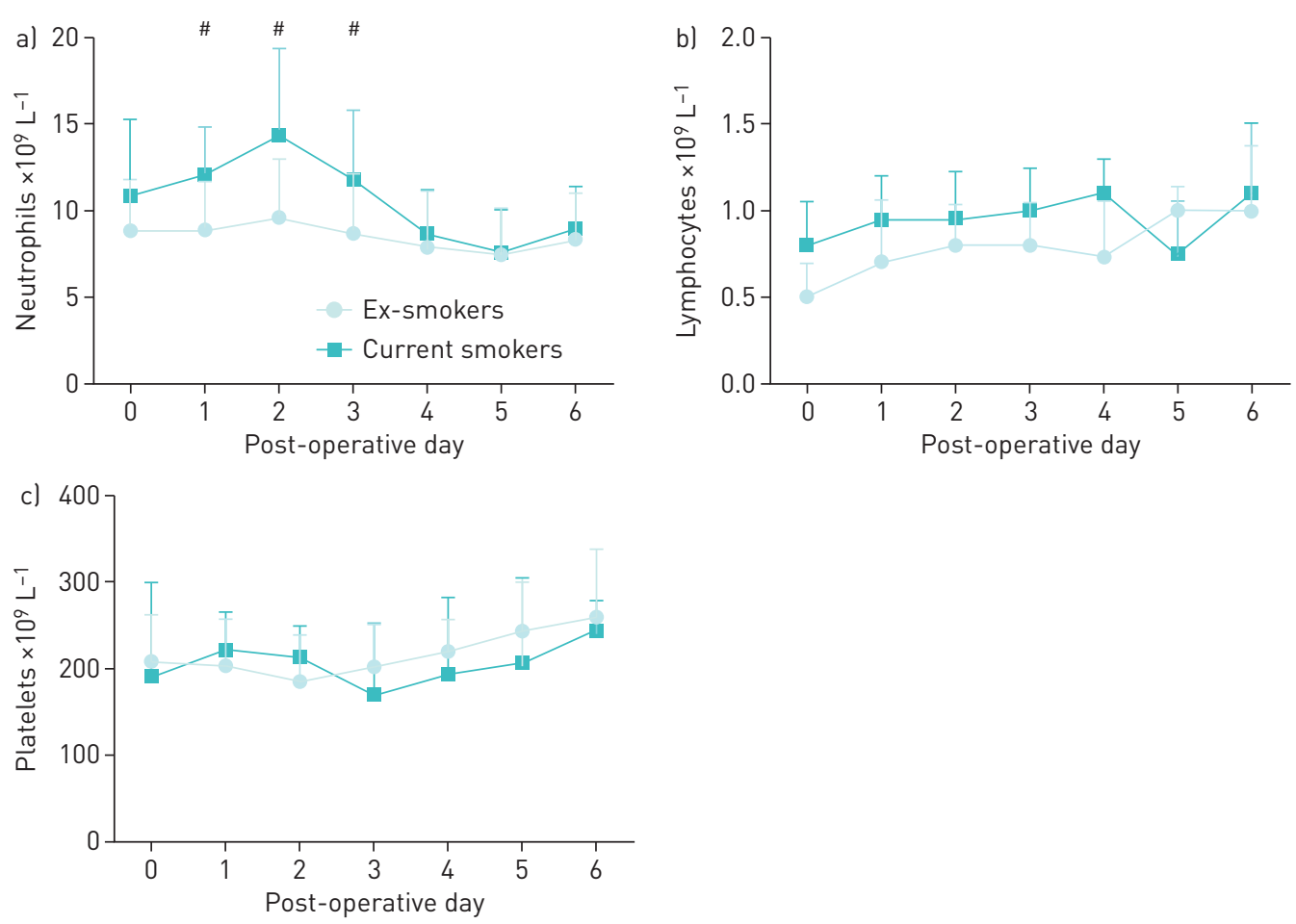

FIGURE 1 Post-operative a) neutrophil counts, but not b) lymphocyte or c) platelet counts, were higher in current smokers than ex-smokers. "\# : time-points were statistically significant using multiple t-tests with the Holm-Šídák method ( $a=5.0 \%)$ to account for multiple comparisons.

levels of total protein, soluble RAGE, SPD, IL-6, IL-8, IL-1 $\beta$, TNF- $\alpha$ or TNFR2 between the groups (supplementary tables E1-E4).

\section{PiCCO measures of alveolar oedema}

EVLWI, PVPI and the arterial oxygen tension $\left(\mathrm{PaO}_{2}\right)$ /inspiratory oxygen fraction $\left(\mathrm{FIO}_{2}\right)$ ratio were similar between both groups pre- and post-operatively (figure 3). EVLWI (median (IQR) 9.80 (7.80-12.18) versus 7.90 (6.25-10.25) $\mathrm{mL} \cdot \mathrm{kg}^{-1} ; \mathrm{p}=0.026$ ) and PVPI (median (IQR) 2.09 (1.78-2.50) versus 1.70 (1.45-2.01); $\mathrm{p}=0.013$ ) were significantly higher in current smokers than ex-smokers on post-operative day 1 . There was no significant difference in the $\mathrm{PaO}_{2} / \mathrm{FIO}_{2}$ ratio on post-operative day 1 (mean \pm SD current smokers $36.7 \pm 10.7$ versus ex-smokers $42.8 \pm 10.7 \mathrm{kPa} ; \mathrm{p}=0.072$ ). There was no significant difference in the cardiac index at any time-point (supplementary table E5).

\section{Clinical outcomes}

Of the 50 patients, $33(66 \%)$ patients required ventilation after surgery with a median positive end-expiratory pressure of $5 \mathrm{cmH}_{2} \mathrm{O}$. On post-operative day 1 only three (6\%) patients remained ventilated after surgery. There was no significant difference between groups in the requirement for ventilation after surgery $(23(64 \%)$ ex-smokers versus $10(71 \%)$ current smokers; $\mathrm{p}=0.75)$ or on post-operative day 1 (two (6\%) ex-smokers versus one (7\%) current smoker; $\mathrm{p}=1.0)$. There was no significant difference between the intra-operative fluid balance between the two groups (median (IQR) ex-smokers $2330(1888-3375) \mathrm{mL}$ versus current smokers 2400 (1189-3088) $\mathrm{mL}$; $\mathrm{p}=0.347)$.

A total of 17 patients (34\%) developed ARDS post-operatively. Eight (57\%) current smokers developed ARDS post-operatively compared with nine $(25 \%)$ ex-smokers $(p=0.031)$ (figure 4$)$. There was no significant difference in the risk of post-operative pneumonia between current smokers and ex-smokers ( $35.7 \%$ versus $27.8 \% ; \mathrm{p}=0.582$ ). There was also no significant difference in the length of hospital admission between current smokers and ex-smokers (median (IQR) 14 (8-25) versus 15 (10-25) days; $\mathrm{p}=0.4487$ ).

Current smokers had a significantly higher mortality post-operatively than ex-smokers, with a median post-operative survival of 421 days in current smokers compared with 771 days in ex-smokers $(\mathrm{p}=0.0225)$ (figure 5); the log-rank HR was 2.034 (95\% CI 1.012-5.298). Patients were followed-up for up to 4 years after surgery, with a significant difference in survival being seen from 9 months post-operatively 

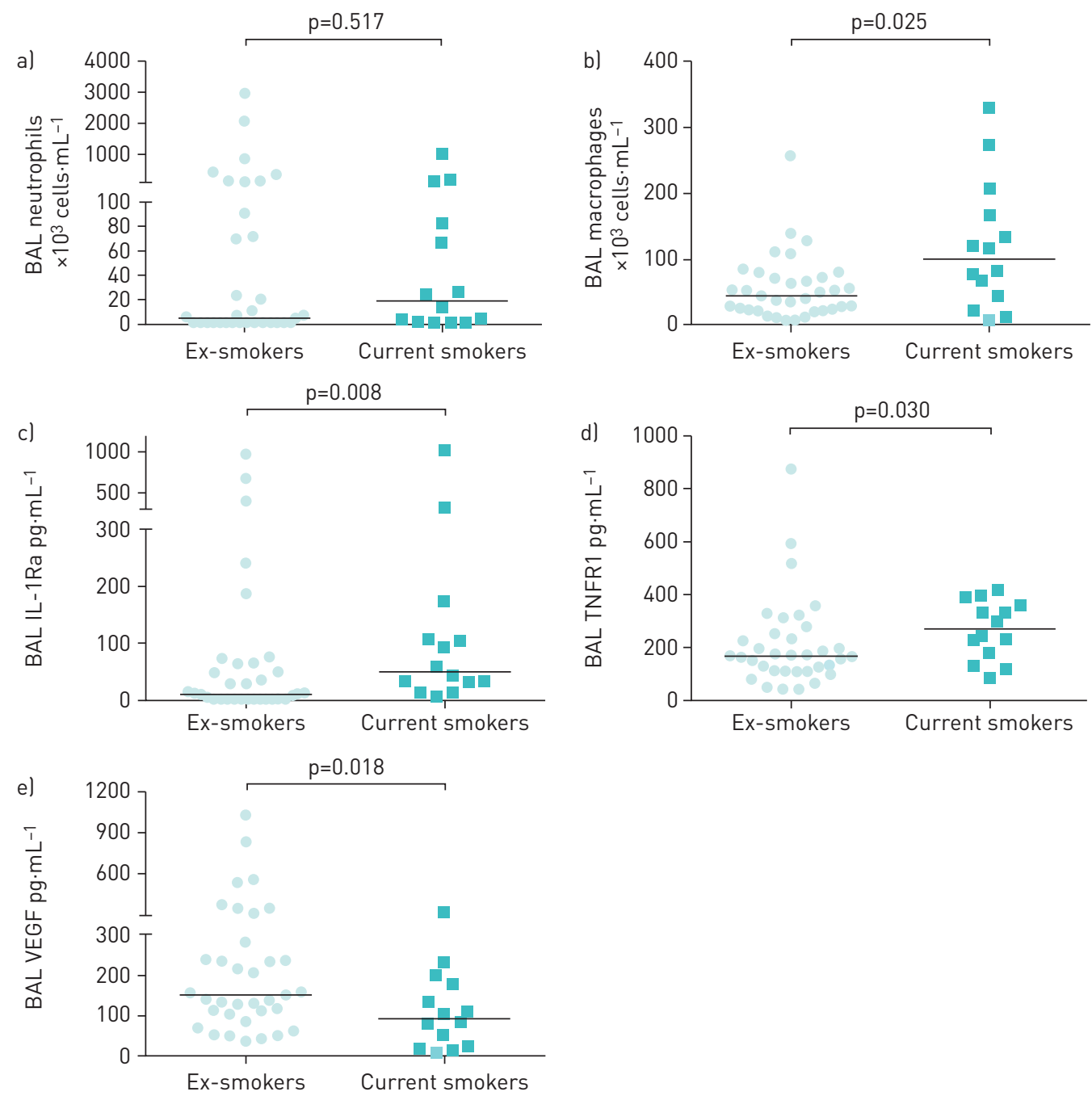

FIGURE 2 There was no difference in bronchoalveolar lavage (BAL) a) neutrophil counts between current smokers ( $n=14)$ and ex-smokers ( $n=35)$, but current smokers had significantly higher concentrations of $b$ ) macrophages, c) interleukin-1 receptor antagonist (IL-1 ral and d) tumour necrosis factor receptor-1 (TNFR1), and lower concentrations of e) vascular endothelial growth factor (VEGF), than ex-smokers.

(ex-smokers two out of $28(7 \%)$ mortality at 9 months versus current smokers five out of $14(36 \%)$ mortality at 9 months; $\mathrm{p}=0.031$ ).

\section{Discussion}

This work demonstrates that patients who continue to smoke prior to oesophagectomy have greater post-operative systemic and lung inflammation evidenced by increased numbers of circulating neutrophils, alveolar oedema, and dysregulated concentrations of cytokines in plasma and BAL fluid compared with ex-smokers. Clinically, this translated into worse outcomes with both higher rates of post-operative ARDS and long-term mortality.

Smoking has been linked to an increased risk of ARDS in a variety of conditions, including sepsis and trauma, but the mechanism is not entirely clear $[8,9,14]$. Smoking has been demonstrated to increase both epithelial and endothelial permeability $[11,12]$, and to be associated with increased alveolar oedema; studies in explanted human lungs found that smokers have more alveolar oedema as measured by lung weight than nonsmokers and that smokers with the highest level of smoke exposure have impaired alveolar fluid clearance [18]. A recent study in healthy volunteers using the lipopolysaccharide challenge model of ARDS suggested that smoking may predispose to an exaggerated disruption of the alveolar-capillary membrane in response to inflammatory insults [14], increasing the permeability of the membrane to protein and replicating findings seen in ARDS. Increased pulmonary permeability appears to be rapidly 

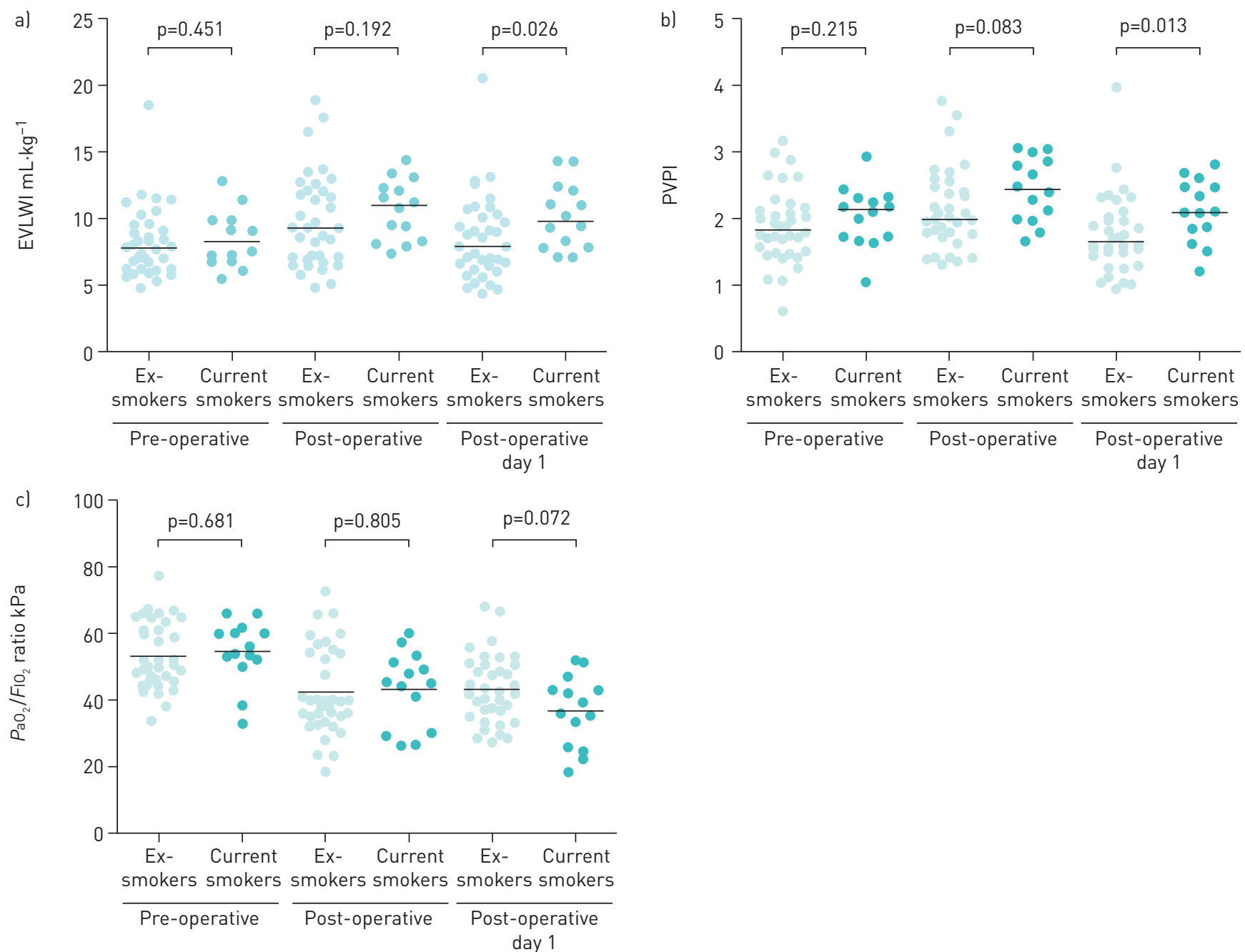

FIGURE 3 Current smokers had higher a) extravascular lung water index (EVLWI) and b) pulmonary vascular permeability index (PVPI) on post-operative day 1 than ex-smokers, but there was no significant difference in c) arterial oxygen tension $\left(\mathrm{PaO}_{2}\right) /$ inspiratory oxygen fraction $\left(F \mid \mathrm{O}_{2}\right)$ ratio.

reversible, with one study demonstrating that the pulmonary epithelial permeability induced by smoking improves within 1 week of smoking cessation [19].

Current smokers in our study had greater levels of inflammatory alveolar oedema as demonstrated by greater post-operative day 1 EVLWI and PVPI, and higher concentrations of IL-1ra and TNFR1, than ex-smokers. Previous studies have demonstrated a higher concentration of BAL IL-1ra and TNFR1 in patients at risk of ARDS, and in those with active ARDS [20, 21]. Higher circulating TNFR1

FIGURE 4 Current smokers had a higher rate of post-operative acute respiratory distress syndrome (ARDS) than ex-smokers $(p=0.031)$.

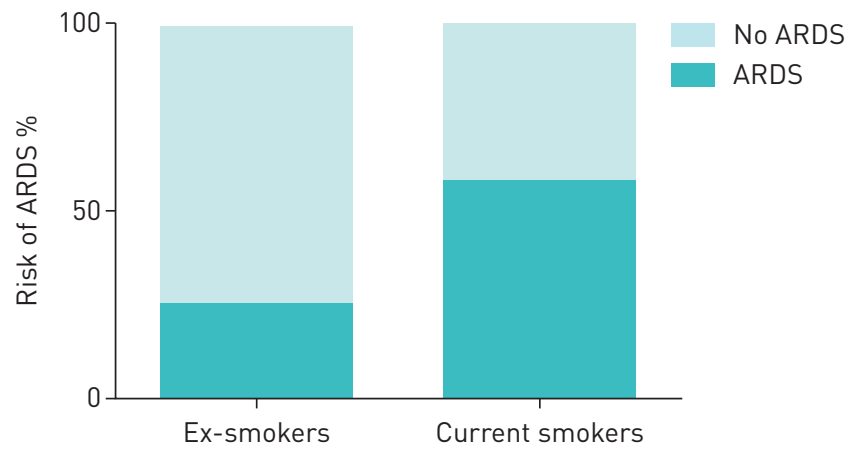


FIGURE 5 Post-operative mortality was significantly higher in patients who were current smokers prior to surgery compared with ex-smokers $(p=0.0225)$.

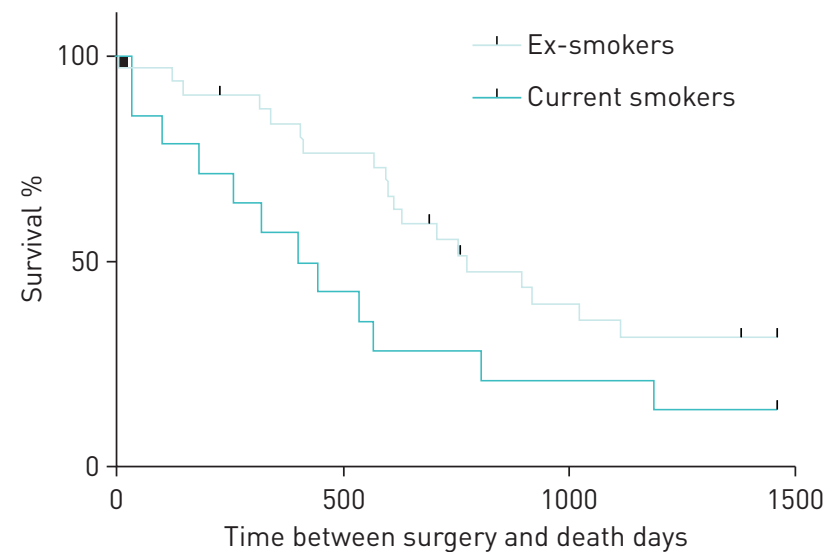

concentrations are also associated with poorer outcomes in patients with ARDS [22]. Meanwhile, BAL VEGF, which acts to protect the pulmonary vasculature and epithelium, was lower in current smokers. Again, low concentrations of BAL VEGF are commonly seen in patients with ARDS [23, 24]. In plasma, pre-operative concentrations of soluble ICAM-1, an endothelial cell adhesion molecule that has been shown to be elevated in smokers and associated with poorer prognosis in patients with colorectal cancer $[25,26]$, were greater in current smokers, but there was no significant difference in post-operative levels. Concentrations of IL-17 were lower in current smokers, a finding which has previously been associated with increased susceptibility to bacterial colonisation in the lungs [27]. Taken together, these findings suggest that the dysregulated inflammation in smokers leads to increased alveolar oedema, ARDS and death post-operatively.

To the best of our knowledge, this study is the first to investigate the relationship between pre-operative smoking status and PiCCO measures of peri-operative alveolar oedema. We found that smokers have evidence of dysregulated alveolar inflammation in the peri-operative period as a direct effect of surgical trauma, which may explain the increased risk of post-operative ARDS. Our finding that risk of pneumonia was similar in both groups suggests that the increased risk of ARDS in smokers undergoing oesophagectomy is not a result of increased susceptibility to pulmonary infection, but perhaps due to a dysregulated response to inflammatory insult.

We found that ex-smokers survive on average almost 1 year longer (350 days) following oesophagectomy than current smokers. We were unable to access death certificate records to establish the cause of death for our patients, but it is likely to include recurrence of the oesophageal cancer and infection. Patients diagnosed with ARDS have increased mortality for at least 2 years following recovery from their acute illness [28], so the increased incidence of ARDS we found in current smokers may directly contribute to increased long-term mortality. There is little data available on the effects of ARDS upon long-term immunoparesis, but studies in patients with sepsis have demonstrated marked effects on the adaptive immune system that may increase susceptibility to development of disease in the future $[29,30]$.

This study does have limitations. First, it is likely that some differences between groups are obscured by the small number of patients studied. The patients in this study only had post-operative BAL performed, so we were not able to investigate smoking-related changes from pre-operative BAL prior to oesophagectomy. Furthermore, data related to modes of ventilation, ventilator settings and lung protective ventilation during anaesthesia were not collected in these patients, all of which may play a role in decreasing the rate of post-operative complications and mortality. In addition, patients self-reported their smoking status and we were not able to carry out any biochemical confirmation (e.g. exhaled carbon monoxide and salivary cotinine), which may have increased the accuracy of the assessment [31]. We do not know the length of time since smoking cessation for the group of ex-smokers and it is likely that the range is relatively broad. Data regarding smoking status were collected at the pre-operative assessment clinic (typically up to 2 weeks prior to surgery) and self-reported, so it is possible that some short-term quitters were included in the current smokers group. There is little consensus on the optimal minimal time prior to surgery for cessation; while studies have shown that airway sensitivity is reduced within 1-2 days of abstinence from smoking [32], others suggest that a period of time ranging from 1 to 6 months is required to see a reduction in post-operative pulmonary complications [33-37]. While some studies have suggested an increased risk of harm when smokers abstain or reduce cigarette consumption close to surgery, this has not been confirmed on meta-analysis, although the number of patients involved in such studies is relatively small $[36,38]$. 


\section{Conclusions}

This study demonstrates that patients who smoke at the time of oesophagectomy have altered pulmonary immune markers post-operatively, with higher levels of inflammatory mediators, and lower levels of protective mediators, similar to those seen in established ARDS. These changes translate into a higher post-operative inflammatory alveolar oedema, greater risk of ARDS and greater long-term mortality. Further research is needed to investigate the optimal timing of smoking cessation prior to surgery, and to evaluate the impact that novel nicotine delivery systems such as "e-cigarettes" have on post-operative inflammation and clinical outcomes.

Author contributions: R.C.A. Dancer and D.R. Thickett conceived the study. D.R. Thickett, G.D. Perkins, F. Gao, O. Tucker and D. Park were involved in design and execution of the trial, which generated the data on which this work is based. S.T. Lugg, P.A. Howells, D. Parekh, A. Scott, R.Y. Mahida and R.C.A. Dancer carried out data analysis. S.T. Lugg, K.A. Alridge and R.C.A. Dancer wrote the first draft of the paper. All authors contributed to revising the draft and have agreed to the final submitted version.

Conflict of interest: None declared.

Support statement: R.C.A. Dancer, DP and D.R. Thickett were funded by the Medical Research Council (grant MR/ M025578/1). D.R. Thickett was also funded by the Wellcome Trust. G.D. Perkins receives support as a NIHR Senior Investigator and Director of Research for the Intensive Care Foundation. P.A. Howells was funded by an unrestricted grant from GlaxoSmithKline.

\section{References}

1 Mantziari S, Hübner $\mathrm{M}$, Demartines $\mathrm{N}$, et al. Impact of preoperative risk factors on morbidity after esophagectomy: is there room for improvement? World J Surg 2014; 38: 2882-2890.

2 Derogar M, Orsini N, Sadr-Azodi O, et al. Influence of major postoperative complications on health-related quality of life among long-term survivors of esophageal cancer surgery. J Clin Oncol 2012; 30: 1615-1619.

3 Turan A, Mascha EJ, Roberman D, et al. Smoking and perioperative outcomes. Anesthesiology 2011; 114: 837-846.

4 Vonlanthen R, Slankamenac K, Breitenstein S, et al. The impact of complications on costs of major surgical procedures: a cost analysis of 1200 patients. Ann Surg 2011; 254: 907-913.

5 Ferguson MK, Durkin AE. Preoperative prediction of the risk of pulmonary complications after esophagectomy for cancer. J Thorac Cardiovasc Surg 2002; 123: 661-669.

6 Tandon S, Batchelor A, Bullock R, et al. Peri-operative risk factors for acute lung injury after elective oesophagectomy. Br J Anaesth 2001; 86: 633-638.

7 Perkins GD, Gates S, Park D, et al. The beta agonist lung injury trial prevention. A randomized controlled trial. Am J Respir Crit Care Med 2014; 189: 674-683.

8 Calfee CS, Matthay MA, Eisner MD, et al. Active and passive cigarette smoking and acute lung injury after severe blunt trauma. Am J Respir Crit Care Med 2011; 183: 1660-1665.

9 Calfee CS, Matthay MA, Kangelaris KN, et al. Cigarette smoke exposure and the acute respiratory distress syndrome. Crit Care Med 2015; 43: 1790-1797.

10 Diamond JM, Lee JC, Kawut SM, et al. Clinical risk factors for primary graft dysfunction after lung transplantation. Am J Respir Crit Care Med 2013; 187: 527-534.

11 Jones JG, Minty BD, Lawler P, et al. Increased alveolar epithelial permeability in cigarette smokers. Lancet 1980; 1 : 66-68.

12 Lu Q, Sakhatskyy P, Grinnell K, et al. Cigarette smoke causes lung vascular barrier dysfunction via oxidative stress-mediated inhibition of RhoA and focal adhesion kinase. Am J Physiol Lung Cell Mol Physiol 2011; 301: L847-L857.

13 Burnham EL, Kovacs EJ, Davis CS. Pulmonary cytokine composition differs in the setting of alcohol use disorders and cigarette smoking. Am J Physiol Lung Cell Mol Physiol 2013; 304: L873-L882.

14 Moazed F, Burnham EL, Vandivier RW, et al. Cigarette smokers have exaggerated alveolar barrier disruption in response to lipopolysaccharide inhalation. Thorax 2016; 71: 1130-1136.

15 Perkins GD, Park D, Alderson D, et al. The Beta Agonist Lung Injury Trial (BALTI)-prevention trial protocol Trials 2011; 12: 79.

16 Perkins GD, Chatterjie S, McAuley DF, et al. Role of nonbronchoscopic lavage for investigating alveolar inflammation and permeability in acute respiratory distress syndrome. Crit Care Med 2006; 34: 57-64.

17 Bernard GR, Artigas A, Brigham KL, et al. The American-European consensus conference on ARDS. Definitions, mechanisms, relevant outcomes, and clinical trial coordination. Am J Respir Crit Care Med 1994; 149: 818-824.

18 Ware LB, Lee JW, Wickersham N, et al. Donor smoking is associated with pulmonary edema, inflammation and epithelial dysfunction in ex vivo human donor lungs. Am J Transplant 2014; 14: 2295-2302.

19 Mason GR, Uszler JM, Effros RM, et al. Rapidly reversible alterations of pulmonary epithelial permeability induced by smoking. Chest 1983; 83: 6-11.

20 Wajant H, Pfizenmaier K, Scheurich P. Tumor necrosis factor signaling. Cell Death Differ 2003; 10: 45-65.

21 Park WY, Goodman RB, Steinberg KP, et al. Cytokine balance in the lungs of patients with acute respiratory distress syndrome. Am J Respir Crit Care Med 2001; 164: 1896-1903.

22 Parsons PE, Matthay MA, Ware LB, et al. Elevated plasma levels of soluble TNF receptors are associated with morbidity and mortality in patients with acute lung injury. Am J Physiol Lung Cell Mol Physiol 2005; 288: L426-L431.

23 Thickett DR, Armstrong L, Millar AB. A role for vascular endothelial growth factor in acute and resolving lung injury. Am J Respir Crit Care Med 2002; 166: 1332-1337. 
24 Abadie Y, Bregeon F, Papazian L, et al. Decreased VEGF concentration in lung tissue and vascular injury during ARDS. Eur Respir J 2005; 25: 139-146.

25 Scott DA, Palmer RM. The influence of tobacco smoking on adhesion molecule profiles. Tob Induc Dis 2002; 1: $7-25$.

26 Alexiou D, Karayiannakis AJ, Syrigos KN, et al. Serum levels of E-selectin, ICAM-1 and VCAM-1 in colorectal cancer patients: correlations with clinicopathological features, patient survival and tumour surgery. Eur J Cancer 2001; 37: 2392-2397.

27 Andelid K, Tengvall S, Andersson A, et al. Systemic cytokine signaling via IL-17 in smokers with obstructive pulmonary disease: a link to bacterial colonization? Int J Chron Obstruct Pulmon Dis 2015; 10: 689-702.

28 Summers C, Singh NR, Worpole L, et al. Incidence and recognition of acute respiratory distress syndrome in a UK intensive care unit. Thorax 2016; 71: 1050-1051.

29 Boomer JS, Shuherk-Shaffer J, Hotchkiss RS, et al. A prospective analysis of lymphocyte phenotype and function over the course of acute sepsis. Crit Care 2012; 16: R112.

30 Cabrera-Perez J, Condotta SA, Badovinac VP, et al. Impact of sepsis on CD4 T cell immunity. J Leukoc Biol 2014 96: 767-777.

31 Hsieh SJ, Ware LB, Eisner MD, et al. Biomarkers increase detection of active smoking and secondhand smoke exposure in critically ill patients. Crit Care Med 2011;39: 40-45.

32 Erskine RJ, Murphy PJ, Langton JA. Sensitivity of upper airway reflexes in cigarette smokers: effect of abstinence. Br J Anaesth 1994; 73: 298-302.

33 Wong J, Lam DP, Abrishami A, et al. Short-term preoperative smoking cessation and postoperative complications: a systematic review and meta-analysis. Can J Anaesth 2012; 59: 268-279.

34 Vaporciyan AA, Merriman KW, Ece F, et al. Incidence of major pulmonary morbidity after pneumonectomy: association with timing of smoking cessation. Ann Thorac Surg 2002; 73: 420-425.

35 Warner MA, Divertie MB, Tinker JH. Preoperative cessation of smoking and pulmonary complications in coronary artery bypass patients. Anesthesiology 1984; 60: 380-383.

36 Bluman LG, Mosca L, Newman N, et al. Preoperative smoking habits and postoperative pulmonary complications. Chest 1998; 113: 883-889.

37 Kotani N, Kushikata T, Hashimoto $\mathrm{H}$, et al. Recovery of intraoperative microbicidal and inflammatory functions of alveolar immune cells after a tobacco smoke-free period. Anesthesiology 2001; 94: 999-1006.

38 Myers K, Hajek P, Hinds C, et al. Stopping smoking shortly before surgery and postoperative complications: a systematic review and meta-analysis. Arch Intern Med 2011; 171: 983-989. 